EstAg 30 (1995) 491-515

\title{
La Convivencia
}

En los próximos años, vamos a padecer una inflación de la palabra "convivencia". El proceso ya se ha desencadenado. Son los mismos que hasta ayer imponían en nombre de Dios la soledad y el silencio quienes se preparan a llevar por las plazuelas su mercadillo de diálogo y convivencia, que, al parecer, es ahora lo rentable. Conviene vacunarse preventivamente para poder asistir al espectáculo tranquilos, regocijados y un tantico, sólo un tantico, sorprendidos. La mejor, la única vacuna realmente eficaz de que dispone el hombre en estos casos es pensar. ¿Cuál es la razón de la convivencia? ¿Dependerá del vaivén de la moda? ¿Por qué y para qué hay que convivir?

Como siempre, tenemos que retrotraernos a nuestra vida, cada cual a la suya, al "hombre de carne y hueso", que diría Unamuno; hacer pie en ella y desde ella pensar. Cuando los nuevos mensajes sean un auténtico guirigay, que lo serán, como ya lo está siendo todo lo relativo al "proyecto", y el discurso sobre la convivencia se haya vuelto trivial, puro hollejo resobado, nuestra salvación será seguir pensando. Y cuando los buhoneros, cansados de su monótona cantilena, recojan sus cacharros y vuelva el "sosegado y maravilloso silencio"1, sigamos pensando, vacunándonos contra la nueva remesa de baratijas con que volverán. Pensar, siempre pensar. No ser nunca doctrinos, carne de catequesis.

Desarrollaré el tema desde tres niveles, o, si se quiere, desde tres ángulos: desde el pensamiento actual, desde el evangelio y desde san Agustín. Trataré detenidamente el primero y aludiré muy raudamente a los otros dos. A lo largo de la exposición, quedarán manifiestas las razones de por qué lo hago así.

1. Miguel de Cervantes, La Galatea, I. III (Clásicos Castellanos 154), Espasa-Calpe, Madrid 1961, I, 204. Los epítetos sosegado y maravilloso aplicados a silencio son un hallazgo definitivo. ¡Genial Cervantes! 


\section{I.- Filosofía}

\section{1.- La relación}

En el mundo hay cosas, muchas cosas. Una clasificación muy antigua, sabida de todos, las divide en minerales, vegetales, animales y hombres. Pero las cosas no están ahí, quietas, aisladas, sin tener que ver nada unas con otras. En realidad, no hay cosas. Una cosa es un ser en sí, independiente de mí, sin referencia a otra cosa, una sustancia. Pero esto es una hipótesis nuestra, una suposición, todo lo verídica que se quiera. Lo evidente es que en torno a mí hay algos que me son ayuda o estorbo, caricia o azote, halago o rozadura; en suma, trebejos, útiles, herramientas para mis fines.

Cada cosa (sigamos con el lenguaje habitual para entendernos más fácilmente) es "un pedazo del universo: nada hay señero, nada hay solitario ni estanco. Cada cosa es un pedazo de otra mayor, hace referencia a las demás cosas, es lo que es merced a las limitaciones y confines que estas le imponen. Cada cosa es una relación entre varias" ${ }^{\text {. }}$ El ser de cada cosa son los rasgos que la oponen a las demás con las que se relaciona, "el conjunto de relaciones, de mutuas influencias en que se hallan todas las demás. Una piedra al borde de un camino necesita para existir del resto del universo"3. "En el nacimiento de una brizna de hierba colabora todo el universo"4. Así se expresaba Ortega y Gasset en 1910, haciéndose cargo con gran lucidez, desde su misma juventud, a los veintisiete años, del gran viraje que estaba dando el pensamiento europeo en todas sus manifestaciones.

Adiós, pues, a la realidad inmutable y única. Habrá tantas realidades como puntos de vista: la realidad de todos los días, o sea, la que nos sirve para andar por casa, la científica, la filosófica, la artística, la literaria, la teológica, la de la moral laica, la de la lingüística, la económica, la política, etc., etc. "No otro, sigue diciendo Ortega, es el sentido más hondo de la evolución del pensamiento humano desde el Renacimiento acá: disolución de la categoría de sustancia en la categoría de relación"s.

\section{2.- El viviente y su medio}

Si esto es verdad de los minerales, lo es mucho más de los seres vivos. Entre ellos y el medio ambiente se establecen infinitas, sutiles e inextricables

2. José Ortega y Gasset, Adán en el paraíso, en Mocedades (=Col. Austral 221), EspasaCalpe, Madrid 19747, 66.

3. Id.: Íb., 75-76

4. Id.: Ílb., 78

5. Íb.,75. 
relaciones; un auténtico tejido vital, una telaraña de vida, web of life, que dicen los ingleses, con sus vanos y nudos, a trozos muy espesos, a trozos distanciados: un campo de conexiones. El viviente y su medio son un todo.

Fue Lamarck el primero que lo advirtió en su "Filosofía zoológica" (París, 1809). De aquí su concepto de "biología general". Según él, "la biosfera no es una simple imagen mental, ni una palabra acuñada por mero paralelismo con atmósfera, litosfera o hidrosfera, sino realidad auténtica"6.

La ecología tiene aquí su justificación, lo mismo que el estructuralismo en biología, dos ramas científicas de principios del siglo pasado. Desde entonces, los conceptos de relación, conexión, estructura, sistema... no han hecho sino extenderse y consolidarse en todas las ciencias. Hoy está claro. La depredación de la selva amazónica alterará el clima y las condiciones de vida de todo el planeta. Lo que pase en las costas de cualquier país mediterráneo afectará a todos y a cada uno de ellos y de ahí sus influencias se expandirán sin limitación alguna.

\section{3.- La relación en las ciencias}

El gran acierto de Saussure en su Curso de lingüística general, publicado póstumamente en 1915, fue ver la lengua como "un sistema en donde todos los términos son solidarios y donde el valor de cada uno no resulta más que de la presencia simultánea de los otros"?.

Durante siglos, desde el I a. C. con Dionisio de Tracia, el estudio gramatical partía de la palabra como unidad básica. En la actualidad, la unidad básica para los lingüistas es la oración. Lo que importa, cualquiera que sea el nivel que se estudie, es descubrir el sistema en el que están integrados los elementos de ese nivel. "Hay que partir de la totalidad solidaria para obte-

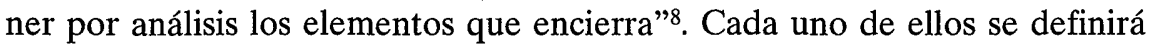
por las relaciones diferenciales con los otros. Será lo que los otros no sean. Cada una de las vocales, por ejemplo, será el haz de rasgos que la diferencian de las demás o haz de rasgos pertinentes. Las lenguas son estructuras, no nomenclaturas.

El método pasó a los estudios de poética. "La Estilística estudia organismos, estructuras sincrónicas de valores. El análisis estilístico actúa sobre los valores de una estructura sincrónica: nada más sincrónicamente orgánico

6. Rafael Alvarado, La trama vital, en $A B C$ 17-11-1988, 3.

7. Curso de lingüística general, traducción, prólogo y notas de Amado Alonso, Editorial Losada, Buenos Aires 19552, 195.

8. Id., Íb., 194. 
que el poema, la más perfecta realización del lenguaje, última posibilidad, última condensación significativa del lenguaje. El fin del estudio estilístico de un poema no es sino su comprensión como perfecto e individual sistema de valores. Hallarle al poema la "unicidad" de su sistema de valores, he ahí el fin (no conseguido) de la Estilística".

He puesto el ejemplo de la lingüística y de la estilística por serme más familiares, pero lo mismo ha ocurrido en las demás ciencias.

\section{4.- Consecuencias de esta nueva visión}

Frente al antiguo mundo de cosas, de elementos con existencia independiente, de sustancias, ha surgido este nuevo de relaciones. En él, yo estoy referido a todo y todo hace relación a mí; dependemos mutuamente. "En un mundo de cosas no tenemos ninguna intervención: él y todo en él es por sí. En cambio, en un mundo de asuntos o importancias, todo consiste exclusivamente en su referencia a nosotros, todo interviene en nosotros, es decir, todo nos importa y afecta"10. Y si todo nos afecta, habrá que intervenir y participar en ello, no volverle la espalda y huir. Se nos derrumba la tradición espiritual de Occidente que hacía de la evitación de todo trato con los hombres y de la huida el principio de santificación. Huir, decían antes; participar, decimos ahora. No cabe cambio más radical.

\section{5.- La relación entre el hombre y el animal: reciprocidad imperfecta}

Alguien está trabajando en una cantera. $\mathrm{Al}$ hacerlo, tiene presentes sus experiencias anteriores. Sabe que, si golpea la piedra con un instrumento apropiado, esta se resquebraja; que, con un preparado de pólvora u otra materia explosiva, puede volarla. Pero la piedra no se entera de lo que hacen con ella; no responde a la acción del hombre sobre ella. La piedra ni hace ni padece. La acción va del hombre a la piedra sin camino de vuelta. Lo mismo podemos decir del árbol. Un hombre se acerca a un chopo y rompe una de sus ramas. Salta una esquirla y le hiere en un ojo. Es un accidente puramente mecánico; no una reacción del chopo maltratado por el hombre.

9. Dámaso Alonso, Poesía española, (Biblioteca Románica Hispánica. II. Estudios y Ensayos 1), Edit. Gredos 1957, 195-196; en Obras completas, Edit. Gredos, Madrid 1989, IX, 163-164. Ahí, en la nota 63, explica Dámaso Alonso sus coincidencias y sus profundas discrepancias con Saussure.

10. Ortega y Gasset, El hombre y la gente (= Col. Austral 1501), Espasa-Calpe, Madrid $1972,51$. 
Todo cambia en nuestro trato con el animal. Aquí la acción, tanto la del hombre como la del animal, va y viene, viene y va. El hombre, al tratar con el animal, antes de ejecutar su acción, cuando la está proyectando, cuenta con la posible reacción de este, la anticipa en su imaginación. Y su comportamiento varía según sea el animal. No es lo mismo coger un ruiseñor que una serpiente, montar un poni o un potro sin domar, pasar junto a un cerdo o junto a un toro bravo. El animal existe para el hombre, pero este también existe para aquel: se son mutuamente, se responden mutuamente, se reciprocan, coexisten, conviven. Cosa que en absoluto se puede decir del trato del hombre con la piedra o con el vegetal.

Pero esta reciprocidad del hombre con el animal es evidentemente muy limitada. El animal responde a un repertorio muy reducido de actos humanos y con un repertorio, también muy reducido, de actos suyos. Es verdad que se puede ampliar esta convivencia, amaestrando al animal, grabándole respuestas inducidas, que por lo mismo dejan de ser suyas, o animalizándose el hombre, poniéndose al nivel del animal. Aun así, nunca se llega a una correspondencia adecuada entre ambos.

\section{6.- La relación entre los hombres: la reciprocidad plena}

Pero he aquí que en mi horizonte hay también hombres, los otros. Veo sus gestos, observo sus acciones, sus movimientos, sus palabras... y concluyo: en ellos hay un yo como el mío; un yo que piensa, quiere y siente igual que el mío. Cada uno de ellos es capaz de responderme tanto como yo a él. La reciprocidad es ahora clara y saturada (expongo muy brevemente la doctrina de Ortega y Gasset en El hombre y la gente). Con el otro (alter) puedo y tengo que alternar. Yo existo para él y él para mí, queramos o no, cualesquiera que sean las intenciones del uno sobre el otro. El otro me aparece como el que me responde tanto como yo a él. El otro me es el reciprocante. Este es el atributo primero y fundamental que en él descubro. Todo lo demás que resulte ser el otro viene después.

La realidad, pues, aludida por la palabra "hombre" solo se me presenta si hay otro ser que me reciproca. Decir hombre es decir, al menos, dos existencias que se reciprocan clara y satisfactoriamente. Decir hombre es decir comunidad, sociedad, como enseñó Husserl, el primero que nos hizo ver con ojos nuevos la convivencia ${ }^{11}$. Yo, solo, no podría ser nunca esa realidad. Para

11. Cf. Edmund Husserl, Meditaciones cartesianas, Ediciones Paulinas, Madrid 1979; Pedro Laín Entralgo, Teoría y realidad del otro, Selecta de Revista de Occidente, Madrid $1968^{2}$, I, 189207, donde expone el pensamiento de Husserl sobre el otro. La obra de Laín son dos volúmenes. En ella estudia varios de los autores aquí citados. 
serlo necesito en torno a mí a otros hombres, al menos potencialmente. Adán en el paraíso, dice el Génesis, "no se encontró el auxiliar que le correspondía" $(2,20)$. Ese echar en falta a alguien que le corresponda plenamente es lo que le delata como hombre. Quien no eche en falta a los otros es que ha reingresado en el reino animal. Videant consules. "El hombre no aparece en soledad -aunque su verdad última es su soledad-; el hombre aparece en la socialidad como el otro, alternando con el uno, como el reciprocante" ${ }^{12}$. Unamuno decía: "Una persona aislada deja de serlo. ¿A quién en efecto, amaría? Y si no ama, no es persona" ${ }^{13}$. Y Antonio Machado escribió: "Poned atención:/ un corazón solitario/ no es un corazón"14.

\section{7.- La alteridad $u$ otredad}

Pero aquí viene la gran paradoja. El otro es otro como yo; es otro, pero yo; es yo, pero otro, por tanto no-yo. Los minerales, los vegetales y animales se me oponen, me ofrecen resistencia. Son, en cierto sentido, no-yo. Sólo en cierto sentido, porque todas esas resistencias me son evidentes, aparecen en mi vida, están dentro de ella. Pero ahora aparece en mi vida alguien que en un sentido está también dentro de ella. Su cuerpo, sus gestos, sus movimien-

12. Ortega y Gasset, ib., 91 .

13. Del sentimiento trágico de la vida, introducción de Pedro Cerezo-Galán (Col. Austral A 312), Espasa-Calpe, Madrid 19935 , 193. "Mi yo vivo es un yo que es en realidad un nosotros; mi yo vivo, personal, no vive sino en los demás, de los demás y por los demás yos; procedo de una muchedumbre de abuelos y en mí lo llevo en extracto, y llevo a la vez en mí en potencia una muchedumbre de nietos" (Íb., 195). "La conciencia de cada uno de nosotros, en efecto, es una sociedad de personas; en mí viven varios yos, y hasta los yos de aquellos con quienes vivo" (Íb., 197). "Y es que no estamos en el mundo puestos nada más junto a los otros, sin raíz común con ellos, ni nos es su suerte indiferente, sino que nos duele su dolor, nos acongojamos con su congoja, y sentimos nuestra comunidad de origen y de dolor aun sin conocerla" (Ílb., 225).

Sobre este tema en Unamuno, cf., además de la obra citada de Laín Entralgo, Julián Marías, Miguel de Unamuno (Col. Austral. 991), Espasa-Calpe, Madrid 19715.

14. Proverbios y cantares, LXVI, en Poesía y prosa (Clásicos Castellanos. Nueva Serie 12), edición crítica de Oreste Macrí, Espasa-Calpe/ Fundación Antonio Machado, Madrid 1989, II, 639.

"El ser con los demás y para los demás pertenece al núcleo mismo de la existencia humana [...]. El ser con los demás, en su significado más profundo y genuino, significa que el hombre no está nunca solo. Su existencia personal está siempre orientada hacia los demás, ligada a los demás, en comunión con los demás. El otro está indudablemente presente a la existencia personal, pero como uno que afecta a la existencia en sus dimensiones más personales. La idea de coexistencia incluye también que la existencia se desarrolla y se realiza junto con otros en el mundo, y que el sentido mismo de la existencia está ligado a la llamada del otro que quiere ser alguien delante de mí, o que me invita a ser alguien delante de él, en el amor y en la construcción de un mundo más humano" (Joseph Gevaert, El problema del hombre. Introducción a la antropología filosófica, Ediciones Sígueme, Salamanca 1976, 46). 
tos, sus ademanes, su mirada, sus palabras... me son evidentes, están en mi vida; pero me delatan una vida que no es mía, sino del otro, y un mundo que no es el mío, sino el suyo. Su yo no es mi yo y su mundo no es mi mundo. Inevitablemente, él estará en su mundo y yo en el mío. Somos dos soledades. Nos somos mutuamente extraños, forasteros. La literatura contemporánea y el cine han tratado con frecuencia este tema.

Yo que esperaba poder comunicarme con él directamente y que él lo hiciera conmigo, los dos en pura y efusiva transparencia, y resulta que somos incomunicantes; que, en realidad, sólo podemos comunicarnos a medias, vislumbrarnos, barruntarnos. La convivencia, que yo creía cosa de coser y cantar, un discurrir suave, como de seda, es erizada y difícil, siempre en un tris de volver a la jungla. El hombre está siempre en camino; se está haciendo hombre o deshaciéndose. La convivencia es un problema y un problema grave, el más grave de todos, porque de su correcta solución depende nuestro crecimiento humano, hacernos personas. No hay obra de arte, ni de pensamiento, ni obra alguna hecha por mano de hombre que pueda compararse con esta. Tan importante es que en ella nos va la vida.

Ahora bien, el otro ha sido siempre el gran desconocido, el ignorado y despreciado. El que está fuera del nosotros, fuera del grupo propio, ha sido tratado a lo largo de los siglos como un bárbaro, sin rostro ni nombre; como una cosa, carne de cañón o acémila de trabajo, tizón para el infierno. Dentro del nosotros, del propio grupo, lo que ha interesado han sido los principios, las abstracciones, las normas, no las personas. Pero estas son la única realidad de veras importante, y el otro, pertenezca o no al nosotros, es persona. Cristianamente, lo único en verdad sagrado

\section{8.- El peligro que es el otro}

El hecho de una convivencia diaria relativamente tranquila puede hacernos olvidar el peligro que es siempre el hombre para el hombre y llevarnos a desatender dimensión tan fundamental de nuestra vida. La damos por supuesta, nos parece un hecho natural, y ni la cuidamos ni la educamos.

Pero supongamos que, en un paseo, allá del fondo del bosque me sale un hombre. No sé nada de él; desconozco sus intenciones. A mi mente acude, más en tiempos de inseguridad, la gama de posibles actos que puede ejecutar. Y esto es terrible, porque el hombre es capaz de todo, de lo más excelso y de lo más depravado. El hombre puede ser ángel de la guarda para el hombre, pero también su demonio. La barbarie humana no tiene límites y siempre encontrará razones humanas y divinas que la justifiquen. Un bárbaro 
encontrará siempre algún filósofo y algún teólogo que justifiquen su barbarie. Ante el otro absolutamente desconocido hay que ponerse en lo peor. Los tuaregs lo hacen. De ahí el ritual tan complicado de su saludo.

El hombre es social, se dice. Pero no seamos ilusos ni simplifiquemos las cosas, entendiendo lo de social exclusivamente en un sentido positivo. No veamos solo el lado bueno de las personas. Hay que ver la realidad, íntegramente. El hombre es social positiva y negativamente, es social y anti-social. Puede darnos un abrazo o una puñalada, ayudarnos en nuestros proyectos o impedírnoslos, a veces hasta enmascarando su acción como interés por nosotros. El hombre es, literalmente, del linaje de las fieras; una fiera que huyó de entre las fieras y aún no ha llegado plenamente a su reino humano: una fiera en trance de humanización. Por eso puede volverse fiera, despertar la fiera que hay en él. No hay más que abrir los ojos y ver cómo el hombre continúa con resabios de selva. También, también en los conventos. No nos hagamos los buenos de la película. No creamos que, por decir muy solemnemente que el Espíritu Santo nos ha convocado a vivir juntos, aquí todo el monte es orégano. Sabemos que no es así.

\section{9.- La convivencia: nosotros}

Difícil y todo, no hay nada humano que no sea difícil e incómodo, la convivencia es una necesidad de la vida humana, porque el hombre es relación y relación, ante todo, con los otros hombres, como acabamos de ver. Unos y otros actuamos entre nosotros, nos respondemos con obras y con palabras, nos reciprocamos, vivimos juntos, nos vivimos. Este -mos expresa muy bien la realidad que es nosotros. Yo y el otro hacemos algo juntos, jugamos o nos pegamos, conversamos o reñimos. Es la primera forma de relación concreta con el otro. Es la convivencia.

Convivir es vivir con, entre vivir, al menos, dos seres, entre existirse, entre mezclar sus vidas. En la convivencia, dos vidas individuales, al menos, se ponen en contacto. Un individuo como tal, sujeto de sus acciones, consciente, responsable de ellas, que hace lo que hace porque para él tiene sentido, entra en relación con otro individuo que tiene los mismos atributos. Hay formas en que la convivencia es máxima: la amistad, la familia, dos amantes.

\section{0.- $T u ́$}

\section{a) Del individuo cualquiera al individuo único}

Ahora bien, ¿qué es lo que pasa cuando en la convivencia frecuentamos el trato con determinada persona? Que esta de sernos un desconocido, 
puede ser aquel hombre con quien nos encontramos en el bosque, pasa a sernos conocido, un individuo único, irreductible a cualquier otro, no sólo en su aspecto externo o en su voz, sino también en sus pensamientos y anhelos, en sus deseos y sentimientos, en sus proyectos y relaciones, en su manera peculiar de encarar la vida, lo que llamamos vocación. ¿Quién es fulano de tal? La contestación que demos a esta pregunta es la mejor prueba del grado de convivencia que con él hemos tenido. Si somos capaces de individualizarlo en unos cuantos rasgos que le diferencien de cualquier otro, no hay duda de que nuestra convivencia con él ha sido intensa; convivencia que ha podido ser, no lo olvidemos, positiva o negativa. La convivencia positiva, el amor, es el mejor camino para conocer a las personas. Un buen ejercicio: intentar describir en unos cuantos rasgos a aquellos con quienes convivimos, comprobando el grado de convivencia que con ellos tenemos.

Pero en el otro, por muy tú que nos haya llegado a ser, por muy tuizado que lo tengamos (permítaseme el neologismo orteguiano), siempre nos quedarán zonas oscuras; algo de él se nos escapará. El saber vital, a diferencia del científico, nunca está concluso; es siempre movedizo e inseguro.

\section{b) La alteridad del tú y del nosotros}

El tú, por muy bien que le conozcamos, sigue siendo otro, con su yo y su mundo propios, incoincidentes con los míos. Y es ahora, precisamente ahora, cuando se me parece como realmente otro. Tú seguirás siendo siempre tú, por muchas coincidencias que haya entre nosotros dos. Por más que intente ponerme en tu lugar, transmigrar a tu punto de vista, nunca lo lograré cabalmente. Habrá siempre en ti un reducto para mí indescifrable. Esto es lo que da su sabor agridulce a la convivencia y lo que la hace fascinante. Todos iguales, ¡qué aburrimiento! Imponer la uniformidad, ¡qué desperdicio de riqueza y qué crimen de lesa persona! La convivencia que hay que promover es precisamente aquella que permita al otro serlo, ser él, "nuevo y distinto, distinto de mí y de todos, él mismo"15. Más aún: hay que promover aquella que no sólo le permita ser él, sino que le ayude a serlo. La comprensión y aceptación del otro en calidad de tal es norma elemental en la nueva concepción del nosotros después de Husserl. Yo tengo que aceptar a los demás en su condición de otros, diferentes cada uno de ellos, pero los demás tienen que aceptarme a mí. La comprensión y aceptación tienen que ser mutuas; tenemos que reciprocarnos en comprensión y aceptación.

15. Gerardo Diego, Brindis, en Versos humanos, Obras Completas, Aguilar 1989, I (Poesía), 297. 
En ese ir siendo tú, haciéndote, tú serás distinto de lo que has sido: mucho o poco, pero siempre distinto. Nunca tú serás lo mismo que eres ahora ni lo seré yo. Es otra razón para que mi conocimiento de ti sea siempre imperfecto. Tú, a la postre, serás siempre para mí un enigma, un misterio. Por eso nos aconseja el evangelio: "no juzguéis y no os juzgarán, porque os van a juzgar como juzguéis vosotros, y la medida que uséis la usarán con vosotros" $(\mathrm{Mt} \mathrm{7,1).}$

Cuando son dos nosotros los que se relacionan, las cosas se complican. Durante siglos, católicos y protestantes se anatematizaron y persiguieron mutuamente, en una loca carrera de "peor eres tú". Fue su forma de relacionarse. Con el Concilio Vaticano II, las cosas comenzaron a cambiar. No pocos dieron por hecha ya la unidad de las Iglesias. Hoy, después de años de reuniones y estudios, comienza a verse lo complicado que es el nosotros cuando tiene frente a él otro nosotros, en este caso el nosotros católico y el nosotros protestante. Comienzan a entenderse las razones de sus diferencias: tantas y tan entretejidas que comienza a hablarse del derecho a ser diferentes en paz y armonía. Es en la mutua alteridad, reconocida y convivida, donde debe producirse la comunión. Este es ya, sin duda, un gran fruto del ecumenismo.

\section{c) La peligrosidad del tú}

Y ¡qué ocurre ahora con el peligro que es el otro cuando es un desconocido? Que persiste, porque su peligrosidad no le viene por ser desconocido, sino por ser otro. El ser desconocido puede llevar su peligrosidad a un grado superlativo. Ahora, en el conocido, está como agazapada, latente, y sólo actúa en formas mínimas por cotidianas; tan mínimas que no las reconocemos como peligro. Y este es quizá el peligro mayor que acecha a nuestra convivencia, el no advertir que, aun la más pacífica, es lucha, tensión, esfuerzo. Si no se está sobre aviso, esos pequeños choques y roces la van erosionando y su deterioro puede llegar a ser grande; incluso puede sobrevenir su derrumbamiento.

Dice Ortega y Gasset: "la armonía ejemplar en una familia ejemplarmente valiosa, cuyos miembros están unidos por los más cálidos nexos de ternura, es sólo un equilibrio resultante, un buen acomodo y adaptación mutua a que han llegado después de haber recibido cada uno los innumerables impactos y choques con el otro, todo lo menudos, relativamente, que se quiera, pero que son, en puridad, una efectiva lucha. En esta lucha hemos aprendido cuáles son las esquinas del modo de ser del otro con las cuales tro- 
pieza nuestro modo de ser; es decir, hemos ido descubriendo la serie innumerable de pequeños peligros que nuestra convivencia con él trae consigo, para nosotros y para él. Es, por citar sólo un mínimo ejemplo, tal palabra, precisamente tal palabra, que no se le puede decir, porque le irrita o le hiere o le azota o le solivianta, etc."16. Estemos mutuamente atentos a nuestras esquinas para no chocar en ellas, para saber evitarlas como buenos conductores.

\section{1.- Él, ella, ello}

En esta relación mutua entre tú y yo, en esta interacción, hablamos con frecuencia de terceras personas, es decir, de los que quedan fuera de nosotros, que somos, en español, nos-otros, distintos de los otros. Nosotros puede incluir a dos o a muchos, pero, a la vez, excluye a los otros.

Hablamos también de ello, del mundo, de las cosas, de la naturaleza y de la cultura. La aparición misma de ese que llamamos mundo objetivo está vinculada al nosotros y a la relación yo-tú, a través especialmente de la palabra, pero no sólo de ella. Son los demás los que nos trasmiten las ideas y creencias, los usos y ritos, las técnicas, la cultura, en suma, de la sociedad en que nacemos. A través de los otros aprendemos a movernos en ese mundo que se nos convierte en realidad; que es para nosotros la realidad. Es ese mundo, pensamos, el que hace posible la convivencia. Pero no es verdad. Ese mundo objetivo es el resultado de una larga convivencia, de siglos de esfuerzo y colaboración entre los hombres. "Lo que llamamos el mundo, el mundo objetivo, es una tradición social. Nos lo dan hecho"17 Las cosas más sencillas, el fuego, el aro, la rueda, la cerbatana, el arado, el remo, el amasar el pan... son condensación de historia multisecular.

En convivencia con los otros, vamos tomando posesión de ese mundo. La lengua materna nos lo inyecta deslindado, catalogado, interpretado y valorado: esto es una silla y esto una mesa, esto un camino y esto un árbol, esto un farol y aquello una estrella, esto se come y esto no, esto se hace y eso está prohibido.

Instalados en esa matriz, vamos decubriendo nuevas correspondencias y estableciendo nuevas conexiones a las que, sin el apoyo de la lengua, quizá no llegaríamos nunca o llegaríamos más lentamente y no con tanta certidumbre. Pero un día descubrimos con sorpresa que en ese mundo de únanimes coincidencias, que es como el alma de la tribu, en ese patrimonio común en

16. Ob. cit., 135 .

17. Miguel de Unamuno, ob. cit., 172. 
que nos movemos tú y yo, aparece una discrepancia y luego otra y otra... Discrepancias que con el paso de los años pueden ir abriéndose más y más. Discrepancias que aumentan cuando se trata de la visión global del mundo, del sentido de la vida, de su dimensión religiosa, de tal religión concreta o de tal punto de esa religión.

Adiós a la unanimidad y concordia, a esa como alma única y corazón indiviso. En sucesivos contactos con otros, descubrimos que coincidencias y discrepancias forman el entramado social de los mortales, siendo suficientes aquellas para que sigamos creyendo que todos estamos en un mismo mundo y, por estar en él, convivimos, incluso con quienes pertenecen a otras culturas. En tiempos de cambios profundos, esas distancias pueden agrandarse, sobre todo en comunidades hasta entonces demasiado rígidas y uniformadas. Será la convivencia la que irá creando, muy lentamente, un nuevo mundo objetivo y común, una nueva alma de la comunidad. Conviene, no obstante, tener presente que ese mundo común será en adelante más reducido que el anterior. El pluralismo es un rasgo caracterísitico de las sociedades avanzadas.

\section{2.- $Y o$}

En estas relaciones con el tú, yo me reconozco, y esto es lo más curioso, como distinto de él. Mi relación, que se dirige a él, vuelve de rechazo hacia mí, como el culatazo tras el disparo, y advierto que el otro me niega. Niega mi modo de pensar, de sentir, de querer. A veces queremos lo mismo, ganar unas oposiciones, por ejemplo, y esto nos enfrenta en una dura competición que nos puede convertir en enemigos para toda la vida. Carlos V y Francisco I coincidían los dos en querer el Milanesado; por eso estaban en guerra. Incluso en estos casos en que el otro coincide conmigo choca y me niega. $\mathrm{Mi}$ convivencia con el tú es un choque constante y en esos choques voy descubriendo mis límites y mi figura concreta de hombre ${ }^{18}$. No es pequeña lección esta que nos da la convivencia. Aprenderla debe ser nuestro propósito de cada día.

Entonces descubro que lo que en mi infancia llamaba yo era un concepto abstracto, sin contenido preciso. Yo creía que mi yo era todos; que todos

18. "Tener conciencia de sí mismo [...] es saberse y sentirse distinto de los demás seres, y a sentir esta distinción sólo se llega por el choque [...], por la sensación del propio límite. La conciencia de sí mismo no es sino la conciencia de la propia limitación. Me siento yo mismo al sentirme que no soy los demás; saber y sentir hasta dónde soy, es saber dónde acabo de ser, y desde dónde no soy" (Miguel de Unamuno, ob. cit., 167). 
eran idénticos a mí, $y$, si alguno discrepaba, era estúpido, falto de sentido común, sin razón.Yo lo llenaba todo (algunos siguen así toda la vida: el otro, el discrepante, carece de razón, de lógica; a saber qué intereses le llevan a pensar como piensa, o qué pecados). Ahora me voy dando cuenta de que no es así. De manera similar, en mis primeros pasos mi cuerpo lo llenaba todo. Fueron los choques con los muebles y las esquinas los que me fueron dando conciencia de mis límites. Los choques con los tús van cercenando y construyendo mi yo. Tú sabes matemáticas, yo no; tú sabes hablar, yo no; tu férrea voluntad pone al descubierto mi carencia de ella; tus reacciones me revelan las mías, tan distintas. Tus cualidades me descubren mis defectos; tus defectos, mis cualidades. Antes yo creía que tú eras como yo, alter ego; otro, pero yo. Ahora veo que es más bien al revés. "Pues el ego concreto nace como alter $t u$, posterior a los tús, entre ellos"19. La primera persona, en contra de lo que tradicionalmente se enseña, es la última en aparecer. Es este un descubrimiento que debemos a Ortega y Gasset ${ }^{20}$.

Pero en este descubrimiento progresivo de mí mismo, encuentro que nunca llego al final; que soy para mí mismo un enigma, un abismo insondable. Es lo que san Agustín repite incansable. "Ni yo mismo soy capaz de abarcar la totalidad de lo que soy"21. "Ante tus ojos, Señor, me he convertido a mí mismo en problema. Y esta es mi enfermedad"22. Además, yo, como los demás, cambio en el decurso de la vida: poco o mucho, pero cambio. Hoy no soy lo de hace unos años. Esto hace imposible el conocerme a mí mismo, a ciencia cierta, en relación con el futuro. "Yo puedo saber, en parte, qué soy ahora; pero no sé qué seré mañana"23.

Del nosotros, pues, vamos al tú, a los tús, y de los tús, como uno de ellos, al yo, pero "con dotes y deficiencias peculiares, con carácter y conducta exclusivos que me dibujan el auténtico y concreto perfil de mí mismo -por tanto, como otro y preciso tú, como alter tu"-24. Enriquecidos con todos estos descubrimientos, tendremos que salir de nuevo a los tús, al nosotros.

\section{3.- La realidad y sus interpretaciones}

En mi análisis de la convivencia, he descubierto al otro como tú, y me he descubierto a mí mismo como yo, distintos, irreductibles, irrepetibles, únicos. Pero, si continúo pensando, puedo hacer otras averiguaciones de no menor calado

19. Ortega y Gasset, $f b ., 142$.

20. Cf. $i b ., 96$ y $135-142$.

21. Confess. X, $8,15$.

22. Íb. X, 33, 50 .

23. Serm. 179,10

24. Ortega y Gasset, Íb., íb. 
Normalmente vivimos a cuenta de lo que se piensa y se dice.Vivimos entre interpretaciones de la realidad que la tradición en la que hemos nacido ha ido forjando y acumulando a lo largo de los siglos, y las tomamos por la misma realidad. ¡Tan habituados estamos a ellas! La sociedad nos las insufla con sus usos y costumbres, con su lenguaje. Son comportamientos que hemos visto estimar, doctrinas que nos han inyectado. Es una red, un entramado cultural, laico y religioso, de partidos, academias, escuelas, medios de comunicación social, sectas, iglesias..., que nos dirige sin que seamos conscientes de ello ${ }^{25}$.

No creamos que estas cosas ocurren sólo en la infancia, cuando aún no se es consciente, o sólo a la gente irresponsable de litrona y droga. Todos, todos, recibimos con la información manifiesta, más o menos controlable, una cantidad no pequeña de información solapada, "empaquetada", implícita, oculta, que se va almacenando en la memoria de forma inconsciente, pero activa. Creemos controlar nuestra vida, pero es esta información la que nos controla. No se trata de ninguna conjura en la sombra para manejar el mundo, no. La información explícita lleva dentro información oculta. La tolerancia, por ejemplo, es una gran idea, pero dentro lleva ímplicita otra detestable: se da por sentado que todas los opiniones tienen el mismo valor. Pero son las personas, no las ideas ni las creencias, las únicas que merecen respeto, cualesquiera que sean sus convicciones. El ecumenismo ha sido una adquisición inestimable de nuestro tiempo, pero de él se extrae inconscientemente una carga explosiva: todas las religiones son intercambiables. El escepticismo y los comportamientos contradictorios que de aquí se derivan están a la vuelta de la esquina. De nuestro entorno cultural extraemos inconsciente, implícitamente, comportamientos, valores, ideas y creencias que se integran, sin que lo advirtamos, en nuestro sistema mental y desde él actúan. Estas dos clases de información forman redes incoherentes de significados que pueden entrar en conflicto y originar personalidades neuróticas.

25. “№ seguimos viviendo de las creaciones de su fantasía [de los primeros hombres], encarnadas para siempre en el lenguaje, con el que pensamos, o más bien el que en nosotros piensa?" (Miguel de Unamuno, ob. cit., 170). En Platón discurre la lengua griega; el latín muerto medieval, en la escolástica; en Descartes, la lengua francesa; en Kant y Hegel, la alemana; en Hume y Start Mill, la inglesa. "Y es que el punto de partida lógico de toda especulación filosófica no es el yo, ni es la representación -vorstellung- o el mundo tal como se nos presenta inmediatamente a los sentidos, sino que es la representación mediata o histórica, humanamente elaborada y tal como se nos da principalmente en el lenguaje por medio del cual conocemos el mundo; no es la representación psíquica, sino la pneumática. Cada uno de nosotros parte para pensar, sabiéndolo o no y quiéralo o no lo quiera, de lo que han pensado los demás que le precedieron y le rodean. El pensamiento es una herencia [...]. Toda filosofía es, pues, en el fondo, filología" (Íb., 305). 
En tiempos de cambios profundos, como los nuestros, todo esto se agudiza. Se ha escrito con razón que el descubrimiento de "la memoria implícita o memoria sin conciencia ha producido en los ultimos años el mayor avance teórico y metodológico de toda la era cognitiva"26.

Estamos viviendo a cargo de la sociedad, de los demás, del se dice, de la gente. Son usos y doctrinas que pueden ser válidos o pueden no serlo. Si lo que se dice es falso, si lo que se valora es ilusorio, estamos falsificando nuestra vida. Necesitamos retrotraernos a nuestro interior, al fondo de nosotros mismos, y, tomando enérgico contacto con la realidad radical, exigirles a todos esos usos y opiniones que "nos presenten sus credenciales de auténtica realidad"27. Habitualmente, vivimos socializados. Incluso el hombre más consciente vive la mayor porción de su vida en la convencionalidad, según lo que le han dicho, conforme a lo que se usa, tal como le han moldeado.

\section{4.- Individuación}

Frente a esta posesión del yo que somos cada uno de nosotros por la sociedad, nos urge liberarnos de ella, desplacentarnos, ser nosotros. Somos diferentes, y esta diferencia no hay que anularla, sino consolidarla y desarrollarla.

$$
\begin{aligned}
& \text { "A distinguir me paro las voces de los ecos } \\
& \text { y escucho solamente, entre las voces, una," } \\
& \text { dijo de sí mismo Antonio Machado }{ }^{28} \text {. }
\end{aligned}
$$

Necesitamos que nuestro comportamiento sea nuestro, nuestras nuestras palabras, nuestros nuestros pensamientos; tener voz personal biográficamente; que se nos distinga por ella, como se nos distingue por la voz fisiológica; que nuestras acciones y palabras lleven nuestra impronta. Es preciso que nos esforcemos en un proceso, siempre abierto, de individuación.

La empresa es ardua. ¿Cómo llevarla a cabo? La individuación del animal es biológica; la del hombre es además, y sobre todo, biográfica. Son experiencias que vamos viviendo a lo largo de la vida, en la familia, en la escuela..., las que nos van individualizando. Hay algunas profundas, radicales, que se convierten en los estratos más hondos de la persona, o remueven los ya existentes y crean un nuevo subsuelo. "Tengo la convicción de que el

26. José María Ruiz Vargas, La memoria humana, Alianza Editorial, Madrid 1994, 221.

27. Ortega y Gasset.: Íb., 87.

28. Retrato, en Campos de Castilla, en Poesía y prosa, edic. citada, II, 492, vv.19-20. 
verdadero «principio e individuación», cuando se trata de personas, son las experiencias radicales" 29 . Son encuentros con personas, a veces inesperados. El contacto con una persona auténtica, en posesión de sí misma, nos enriquece y hace que nos poseamos también nosotros, que seamos más libres. Nada mejor para ser nosotros mismos que tomar lo que Laín Entralgo llama "vitamina P", "vitamina persona". "Cada vez, dice, que nos es dado tratar de cerca a un hombre en quien se está realizando auténticamente su condición de persona -no es tan fácil; muchos no pasan de ser personajes o personajillos-, y más cuando esa persona nos abre su ser o está dotada de gran simpatía vital, sentimos en nuestro interior una suerte de inédita conciliación o reconciliación con la vida. ¿Cuántos deprimidos o cansados de ella dejarían de serlo si el mundo en torno les ofreciese en dosis suficientes esa roborante vitamina P?"30. También la convivencia diaria, si se vive con personalidad propia, lejos de la manada, es factor de individuación. Son también algunos libros que nos llenan el alma y nos abren horizontes nunca antes soñados ${ }^{31}$. Es la contemplación de la naturaleza, un paisaje, una puesta de sol, una noche estrellada que nos llena de preguntas, o la contemplación de una obra de arte que nos sume en pensamientos abisales. Es la meditación personal, implacable y asidua, sometiendo a juicio lo divino y humano, también las propias reflexiones; sobre todo, estas.

\section{5.- Solidaridad}

La individuación no es individualismo ni egoísmo. Quien así lo crea no se ha enterado de nada. Porque quien haya descubierto en el otro al tú y en relación con el tú su propio yo, verá que este es relación con el contorno, cielo y tierra, vegetales, animales y los otros hombres, especialmente con estos; que está, a nativitate, abierto a lo otro que él, a los otros.

Ser relación no quiere decir relacionarse. Lo primero no depende de nosotros; lo segundo, sí. El hombre tiene el raro privilegio de poder ir contra sí mismo y negar su condición humana, de quitarse la vida incluso. El hombre puede renunciar a toda relación humana, huir a la montaña y ser fiera

29. Julián Marías, Tratado de lo mejor. La moral y las formas de vida. Alianza Editorial, Madrid 1995, 142.

30. Pedro Laín Entralgo, Esperanza en tiempo de crisis, Galaxia Gutenberg/ Círculo de Lectores, Barcelona 1993, 275.

31. Cf. Mariano Yela, El libro y la formación de la individualidad, en Fernando Lázaro Carreter (Coord.), La cultura del libro, Fundación Germán Sánchez Ruipérez/ Ediciones Pirámide, Madrid 1983, 101-114. 
entre las fiertas, renunciando a su crecimiento como tal hombre. Si, además, los que se atribuyen la función de guías lo han robotizado haciéndole creer que eso es el paraíso recobrado, creerá que ha conseguido el no va más de la perfección. Hay muchas formas de suicidio, algunas muy sutiles. La más peligrosa es esta que se disfraza como una forma superior de vida, si no como la única forma de vida auténtica.

En consecuencia, el proceso de individuación no se hace al margen de los otros, en el aislamiento, sino en relación con ellos. Somos relación; esta es nuestra sustancia en cuanto hombres. Y si somos relación, somos indigentes, menesterosos de los demás. Para ser yo mismo necesito de lo otro que yo, especialmente de los otros, y estos, por lo que entreveo en mi relación con ellos, me necesitan a mí. Nos necesitamos mutuamente, no con una necesidad externa, sino intrínseca, constitutiva. Sin los otros no llegaré a ser nunca yo, ese personaje que tengo que ser porque es mi vocación; ese personaje que quiero ser. Por eso del yo descubierto salgo ahora al nosotros, dándole un sentido más humano, más abarcador, más rico y vivo, dispuesto a construir con ellos un hogar común y vividero.

Nada humano debe serme ajeno; nada de lo que pasa en el mundo, humano o no, debe serme ajeno. Somos vasos comunicantes. Los demás influyen en mí y yo influyo en ellos. John Donne decía que cuando moría un hombre, dondequiera que fuese, y él se enteraba, sentía su vida malherida, disminuida. Hay que mantener viva la sensibilidad a la opresión del hombre por el hombre, allí donde se produzca, siempre que la preocupación por el lejano no sea olvido del vecino; hallarse en continua disponibilidad ante los otros, sin descuidar, claro está, la propia vocación. Individuación y solidaridad, solidaridad e individuación. No una antes que la otra, sino las dos a un tiempo, indisolublemente unidas. Son la dos caras de una misma moneda, el haz y envés de una misma hoja.

Bien lo dijo Ortega en su primer libro (1914): "yo soy yo y mi circunstancia, y si no la salvo a ella no me salvo yo"32. Y Unamuno, al que a veces se le hace sin razón alguna solipsista, escribió: “¿singularizarme? Vamos.../ Somos todos de consuno/ y en la piña que fraguamos/ yo soy nos-otro, nosuno" 33 . No se es hombre en solitario, sino en unión con los otros. En piña,

32. Meditaciones del Quijote, Comentario por Julián Marías, Ediciones de la Universidad de Puerto Rico - Revista de Occidente, Madrid 1957, 43-44

33. Cancionero, 519, en Poesía completa (3), Alianza Editorial, Madrid 1988, 518. "El sentimiento de solidaridad parte de mí mismo; como soy sociedad, necesito adueñarme de la sociedad humana; como soy un producto social, tengo que socializarme y de mí voy a Dios -que soy yo proyectado al Todo- y de Dios a cada uno de mis prójimos" (Id., Del sentimiento trágico de la vida, edic. cit., 280). "Y ser perfecto es serlo todo, es ser yo y ser todos los demás, es ser 
pero siendo cada uno él; un yo que se siente semejante a los otros, identificado con su condición de hombres y solidario de ellos (nos-uno), pero que afirma a la vez su alteridad (nos-otro). Son muchos los textos literarios en los que aparece esta doble dimensión del hombre, individualidad y solidaridad, empezando por el más excelso de todos ellos, el Quijote. Recordemos tan sólo estos versos de Jorge Guillen: "Con la luz, con el aire, con los seres/ vivir es convivir en compañía./ Placer, dolor: yo soy porque tú eres"34.

humanidad, es ser universo. Y no hay otro camino para ser todos los demás sino darse todo, y cuando todo sea en todo, todo será en cada uno de nosotros" (Ib., 283). "Cuanto más soy de mí mismo, y cuanto soy más yo mismo, más soy de los demás; de la plenitud de mí mismo me vierto a mis hermanos, y al verterme a ellos, ellos entran en mí" (Íb., 285). "Puede uno destacarse fuertemente de otros, en cuanto individuo, siendo como un crustáceo espiritual, y ser pobrísimo de contenido diferencial. Y sucede más aún, y es que cuanta más personalidad tiene uno, cuanta mayor riqueza interior, cuanto más sociedad es en sí mismo, menos rudamente se divide de los demás" (Ib., 193). "Una formidable corriente de dolor empuja a unos seres hacia otros, y les hace amarse y buscarse, y tratar de completarse, y de ser cada uno él mismo y los otros a la vez [...]. El alma de cada uno de nosotros no será libre, mientras haya algo esclavo en este mundo de Dios, ni Dios tampoco, que vive en el alma de cada uno de nosotros, será libre mientras no sea libre nuestra alma [...]. La miseria propia es tanta, que la compasión que hacia mí mismo me despierta se me desborda pronto, revelándome la miseria universal [...], y se vierte a compadecer los males ajenos y ejercer caridad [...]. Y es que no estamos en el mundo puestos nada más junto a los otros, sin raíz común con ellos, ni nos es su suerte indiferente, sino que nos duele su dolor, nos acongojamos con su congoja, y sentimos nuestra comunidad de origen y de dolor aun sin conocerla. Son el dolor, y la compasión que de él nace, los que nos revelan la hermandad de cuanto vivo y más o menos consciente existe [...]. Y esa hermandad nos revela la paternidad de Dios, que Dios es Padre y existe. Y como Padre ampara nuestra miseria" (Íb., 224-225).

34. Aire nuestro III, Homenaje, Barral Editores, Barcelona 1978, 556

Desde aquí podemos avanzar hacia una nueva comprensión de la persona y la comunidad. "Su objeto central no lo constituye ni el individuo ni la colectividad, sino el hombre con el hombre. Únicamente en la relación viva podremos reconocer inmediatamente la esencia peculiar del hombre [...]. Si consideramos al individuo en sí, entonces llegaremos a ver tanto del hombre como vemos de la luna; sólo el hombre con el hombre es una imagen cabal. Si consideramos la totalidad en sí, entonces veremos tanto del hombre como vemos de la vía láctea; sólo el hombre con el hombre es una forma perfilada. Si consideramos el hombre con el hombre, veremos, siempre, la dualidad dinámica que constituye el ser humano [...], y siempre los dos a una, completándose con la contribución recíproca, ofreciéndonos, conjuntamentre, al hombre [...]. Podremos aproximarnos a la respuesta de la pregunta "¿qué es el hombre?" si acertamos a comprenderlo como el ser en cuya dialógica, en cuyo "estar-dos-en- recíproca-presencia", se realiza y se reconoce cada vez el encuentro del "uno" con el "otro" (Martín Buber, ¿Qué es el hombre? , Fondo de Cultura Económica, Madrid 1976 ${ }^{9}, 150-151$.

Cf. Martín Buber, Yo y tú, Caparrós Editores, Madrid 1994; Emmanuel Levinas, Totalidad e infinito, Ediciones Síguene, Salamanca 1977; id., Humanismo del otro hombre, Siglo XXI Editores, Madrid 1974; Emmanuel Mounier, Introducción a los existencialismos, Ediciones Guadarrama, Madrid 1973², 106-151; id., Manifiesto al servicio del personalismo, Taurus Ediciones, Madrid 1976 ${ }^{4}$; Carlos Díaz, Persona, en Adela Cortina (dir.), 10 palabras clave en ética, Editorial Verbo Divino, Estella (Navarra) 1994, 289-326; Xavier Zubiri, Estructura dinámica de la realidad, Alianza Editorial/ Fundación Xavier Zubiri, Madrid 1989, 247-275; id., Sobre el hombre, Alianza Efditorial/ Sociedad de Estudios y Publicaciones, Madrid 1986, 223-341; id., El hombre y Dios, Alianza Editorial/ Sociedad de Estudios y Publicaciones, Madrid 1985², 63-74; 


\section{6.- De la soledad a la convivencia}

Durante siglos, los religiosos fueron educados para la soledad y el silencio. La convivencia, la relación con los hombres, también con los religiosos, era lo que había que evitar. "Cuantas veces estuve entre los hombres, volví menos hombre", dice una sentencia del Kempis, maestro de tantas generaciones de almas devotas ${ }^{35}$. No sólo cuando fui a pecar, sino también cuando fui a predicar; siempre.

El sabio se basta a sí mismo, se repetía desde los griegos. ¡Falso! Sabio es quien, llegando al fondo de sí mismo, se ve como indigente, como queriendo ser y no pudiendo serlo si los demás no le ayudan (los creyentes vamos más allá: no pudiendo serlo sin la ayuda de Dios). Sabio es quien oye el grito de los demás, que, como él, quieren ser, pujan hacia su plenitud, pidiendo ayuda, porque sin ella no pueden serlo. Sabios son los que desde su indigencia se proponen ser en solidaridad, en un proyecto común de ayuda mutua, y tienen el coraje de realizarlo.

El hombre se perfecciona en la soledad, decían los espirituales. A solas cada uno con Dios solo, solus cum Solo. ¿Dónde dice esto el evangelio? El evangelio habla siempre de comunidad y nos orienta hacia los demás. Nuestra oración específica, la que nos identifica como discípulos de Jesucristo, es comunitaria, aunque la rece uno solo: "Padre nuestro". Y las bienaventuranzas, el que pudiéramos llamar código de la nueva alianza, aunque no son propiamente un código, están formuladas en plural, no en singular: "dichosos", no "dichoso".

Necesitamos corregir a los maestros del pasado, dar media vuelta a nuestra orientación: no huir, sino convivir. Necesitamos formarnos para la convivencia, crear una nueva paideia y un nuevo estilo de vida que aúne convivencia y soledad, palabra y silencio.

Julián Marías, Antropología metafísica, Ediciones de la Revista de Occidente, Madrid 1973; id., La estructura social, Ediciones de la Revista de Occidente 1972, 249-304; id., Mapa del mundo personal, Alianza Editorial, Madrid 1993; Vicente Aleixandre, Historia del corazón, en Obras completas, prólogo de Carlos Bousoño, Aguilar, Madrid 1968, 679-790, en especial los poemas En la plaza, pp.711-713, El poeta canta por todos, pp. 716-718, y La oscuridad, 727-728, aunque no es fácil elegir. Léase el prólogo de Carlos Bousoño, en especial pp. 13-49.

35. Imitación de Cristo, traducción de Fray Luis de Granada, Aguilar, Madrid 1989, primer tratado, dice textualmente: "Siempre que fui a los hombres, volví menos hombre. Lo cual experimentamos por cierto cuando mucho hablamos". c. 20, 63 . 


\section{II.- Evangelio}

\section{7.- La convivencia evangélica y su actualización}

Son muchos los textos en los que los evangelios hablan de la convivencia. ¿De qué otra cosa se habla en ellos sino del amor mutuo, de la fraternidad, de la igualdad, del mutuo servicio...? No es necesario citarlos, sí meditarlos; redescubrir los valores comunitarios que hay en ellos. Durante los últimos siglos, se los leyó exclusivamente desde el individualismo religioso. Hay aquí una hermosa tarea personal y comunitaria.

Pero todos esos textos hay que vivirlos en la realidad actual, desde la comprensión que hoy tenemos del hombre; hay que encarnarlos, dar carne a su osamenta (en su momento la tuvieron), llenarlos de contenido viviente, determinar sus valores efectivos. De lo contrario, los dejamos flotando en el vacío, como puras fórmulas abstractas. El evangelio nos orienta, nos señala la dirección en la que debemos caminar; pero no nos da el modo concreto de hacer camino, nuestro camino, que, como dijo Antonio Machado, "se hace al andar". Somos nosotros los que tenemos que andar aquí y ahora.

"Amaos", nos dice el evangelio. Pero el amor es una palabra abstracta, que se ha vivido de manera muy distinta según las épocas y las personas. Nosotros tenemos que amar aquí y ahora, desde nuestra realidad, en el nivel histórico en que estamos, teniendo en cuenta la imagen que el hombre actual tiene de sí mismo y su manera de relacionarse con los otros. Hay formas de caridad del pasado que hoy serían injusticias manifiestas. Por esto Pablo VI invitaba a las antiguas instituciones de asistencia y beneficiencia, nombre este último que chirría en los oídos actuales, a renovarse capacitando al personal sanitario y modificando sus estructuras. "Será necesario, dice, en términos absolutos, dejar aquellas formas que significan imposición, paternalismo, improvisación, ligera falta de preparación"36; es decir, hay que actuar de acuerdo con la idea actual de la dignidad humana y la justicia. Los antiguos asilos cumplieron una buena función social en su tiempo, pero son ya historia. El tratamiento que en ellos se daba a los ancianos sería hoy intolerable por injusto. Recuérdese El concierto de san Ovidio de Buero Vallejo.

\section{8.- Dos ejemplos de san Pablo}

Dos ejemplos de san Pablo aclararán lo que quiero decir. Sus cartas son un himno constante al amor. Baste como muestra 1Cor 13, 1-13. Pero un

36. Pablo VI, en Ecclesia 22-11-69, 11(1599). 
buen día Onésimo, esclavo de Filemón, huye de casa tras cometer un robo. Conoce a Pablo y se hace cristiano. También Filemón había sido convertido por Pablo. Este, usando de su confianza con uno y otro, trata de reconciliarlos. Onésimo vuelve a casa de Filemón con una bellísima carta de Pablo para este. Pablo vivía el amor cristiano, pero ni por un momento se le ocurrió abolir la esclavitud (la ocasión se le presentó en bandeja), condición para nosotros evidentemente injusta y negadora de la dignidad humana. ¿Quién se atrevería a proponer hoy esta carta, en el diálogo social, como modelo de relaciones laborales? Los documentos oficiales de la Santa Sede y de las Conferencias Episcopales sobre el tema no la mencionan. Por algo será.

Pues ¿qué decir del famoso pasaje de Ef 5, 21-33? "Las mujeres sean dóciles a sus maridos en todo [...]. Los maridos deben amar a sus mujeres como a su propio cuerpo?” ¿Quién se atreve hoy a leer esta carta en la celebración del matrimonio? Cuando, siguiendo la liturgia, se lee en la iglesia, las piadosas mujeres que la oyen se soliviantan. Pablo no es santo de su devoción. No hablemos de las feministas. En realidad, la carta no es de Pablo, sino de sus discípulos; pero es un testigo, en cualquier caso, de la mentalidad de la Iglesia primitiva. La sumisión de la mujer al marido lo enseña el Apóstol en 1 Cor 11,2-16. En Gál 3,27-28 afirma rotundamente la igualdad de sexos, así como la de rezos y estamentos sociales; pero en una igualdad "en Cristo": todos -judíos y griegos, esclavos y libres, varones y mujeres- se han revestido de Cristo en el bautismo: todos son ya "uno". Para Dios no existen esas diferencias: "Pagará a cada uno según sus obras... Dios no tiene favoritismos" (Rom 2,6-11), idea que está ya en el AT y se repite en el NT.

\section{9.- Historicidad del cristianismo}

Evidentemente, estos textos no son nuestros textos sobre estos temas. Pablo vivía, de eso no cabe la menor duda, el amor de Cristo, y lo vivía intensamente. "El amor de Cristo nos apremia" (2 Cor 5, 14); pero lo vivía de acuerdo con su mentalidad, de acuerdo con todo el sistema de sus ideas y creencias, conscientes e inconscientes, ya que es este el que en realidad actúa. Ni por un momento se le ocurrió dudar de que los esclavos y las mujeres tenían que obedecer: ese era su deber, ese era el designio de Dios. Tardarán siglos en ir apareciendo resquicios por los que se colarán e irán tomando forma y densidad nuevas ideas al respecto.

Los cristianos tendemos a creer que todo está dicho en la Sagrada Escritura. A los de otras tradiciones les pasa lo mismo respecto a sus libros sagra- 
dos. Pero esto no es verdad. Nos separan de ella muchos siglos de historia. Amemos, convivamos; pero desde hoy, desde los actuales conocimientos sobre el hombre, desde nuestra realidad. No nos quedemos en generalidades, en abstracciones. Echemos pie a tierra, andemos por ella, conózcamosla y comprometámonos en su transformación siguiendo a Jesucristo.

\section{III.- San Agustín}

\section{0.- La comunidad agustiniana}

De san Agustín pudiéramos citar muchos textos sobre la comunidad y la caridad. Citaré solamente uno, el comentario al salmo 132. El salmista canta la reunión del pueblo en asamblea litúrgica y, en general, la unión fraterna como bendición de Dios y vida. Es, dice, como el aceite con que se unge la cabeza del Sumo Sacerdote; como el rocío del monte Hermón. Como ellos, va penetrando suavemente y difundiéndose. $\mathrm{El}$ aceite que baja por la barba de Aarón desde su cabeza hasta la orla de su vestido dispara la exégesis de Agustín, enrevesada, pero muy a propósito para lo que quiere transmitir. Él fundó sus monasterios para responder a las necesidades de la Iglesia; en concreto, para rehacer la unidad rota por los donatistas. La cabeza del Sumo Sacerdote es figura de Cristo. La orla del vestido es el gorjal, la parte que rodea el cuello, figura de los monasterios, como la vestidura lo es de la Iglesia. De la cabeza baja el aceite, el Espíritu que produce la unidad, a la barba, a los apóstoles y a los mártires; de aquí pasa al gorjal, donde se termina (perficitur) el vestido, es decir, a los monasterios (los monjes son los sucesores de los mártires), donde se vive la perfección de la unidad, y de ellos al vestido, a la Iglesia. Al ponerse la túnica, la cabeza entra por el gorjal. Cristo, cabeza de la Iglesia, se viste de ella introduciéndose por "la concordia fraterna" que se vive en los monasterios ${ }^{37}$. La unidad que se vive en los monasterios tiene que salir fuera para rehacer la unidad de la Iglesia. ¡Hermoso proyecto comunitario!

Vivamos en unidad, convivamos. Que nuestra unidad sea manifiesta y cree unidad entre los hombres. Que nuestra convivencia sea luz en la noche y cree convivencia. Pero ¿cómo vivir en unidad? ¿Cómo convivir en paz? ¿Cómo dar contenido concreto a estas fórmulas vacías? ¿Nos atendremos a san Agustín, al contenido que él les daba?

37. Cf. Enarr. in ps. 132, 7-9. 


\section{1.- San Agustín, hombre de su tiempo}

Toda vida humana queda inscrita en unas fechas, la de su nacimiento y la de su muerte; fechas que no son algo extrínseco a ella, un accidente, sino su sustancia. San Agustín está inscrito en su tiempo, que es parte de él, y nosotros en el nuestro. Ni él puede saltar fuera de su sombra ni nosotros de la nuestra. Pudiéramos repetir las palabras del padre Abrahán al rico epulón: "entre nosotros y vosotros se abre una sima inmensa, así que, aunque quiera, nadie puede cruzar de aquí hasta vosotros ni pasar de ahí hasta nosotros" (Lc 16,26). Eso de que su tiempo y el nuestro son parejos es una chochez. Tales aproximaciones desconocen en realidad los dos términos que comparan.

Volvamos a los dos ejemplos citados de san Pablo y lo veremos claro.

"La paz de todas las cosas es la tranquilidad del orden" 38 , dice san Agustín. Cada cosa tiene su puesto, su lugar, el que Dios le ha asignado. Estar cada cosa en su lugar es el orden : el súbdito abajo, obedeciendo; el superior arriba, mandando. Mantenerse bien encajada en él, arregostada, sin ni siquiera asomos de abandonarlo, es la paz. Siglos más tarde, lo dirá Fray Luis de León en forma insuperable: "porque si están (las partes de una socie$d a d$ ) bullendo para desconcertarse, y como forcejeando entre sí para salir de su orden, aun antes que consigan su intento y se desordenen, aquel mismo bullicio suyo y aquel movimiento destierra la paz de ellas; y el moverse o el caminar a la desorden, o siquiera el no tener en la orden estable firmeza, es sin duda una especie de guerra" 39 .

Agustín explica con una serie de ejemplos en qué consiste la paz, entre ellos este: "la paz doméstica es la ordenada concordia, en el mandar y en el obedecer, de los que cohabitan" 40 .

Así, pues, que el paterfamilias siga disfrutando de su omnímodo poder de vida y muerte, ius vitae et necis, que dice el derecho romano ${ }^{41}$. Si por conservar la disciplina familiar y la concordia de los suyos, tiene que azotar a alguno de ellos ${ }^{42}$, "hágalo por amor" 43 . Que los esclavos sigan siendo escla-

38. San Agustín, De civ. Dei XIX, 13, 1.

39. De los nombres de Cristo., 1. 2, Príncipe de la Paz, Obras Completas castellanas, BAC, Madrid 19512, 587-588; cf. José Vega, La vocación agustiniana. El proyecto filosófico- monástico-sacerdotal de san Agustín, Estudio Agustiniano, Valladolid 1987, 194-201.

40. San Agustín, f́b. íb.

41. Respecto a las comunidades religiosas, ténganse en cuenta estos textos, entre otros::"obedézcase al prepósito como a un padre [...]; mucho más al presbítero que cuida de todos vosotros" (Regla 7, 44). "El que os preside [...] mantenga, complacido, la disciplina; impóngala por el temor. Y aunque ambas cosas sean necesarias, prefiera más ser amado por vosotros que temido, pensando siempre que ha de dar cuenta de vosotros a Dios" (Íb., 7,46).

42. Cf. Confess. IX, 9,20; De civ. Dei. XIX, 16.

43. In ep. Joan. VII, 8 y 11; pero cf. Ep. 95,3 , donde duda de la eficacia de los castigos corporales. 
vos in saecula saeculorum, amen, y al que Dios se la dé san Pedro se la bendiga. "La condición de esclavitud, afirma Agustín, se le impone con justicia al pecador [...]. Es el pecado, no la naturaleza, el que la ha merecido"44. Tras burros, apaleados. Algo, sin embargo, quizá hayamos progresado. Aristóteles afirmó que los esclavos lo eran por naturaleza; Agustín, que por pecadores. Noé maldijo a su hijo Cam, que, al verle desnudo, fue a contárselo a sus hermanos: "Sea el último siervo de sus hermanos" (Gn 9, 25). Aquí aparece por primera vez la palabra siervo en la Biblia. Aquí está la causa de la esclavitud, razona Agustín. Los vencidos en una guerra, sigue razonando, pueden según derecho ser ajusticiados. Si se les perdona la vida, contentos pueden quedar y agradecidos a su señor. ¡Salve, buana! Los vencidos o son los malos o son los buenos. Si aquellos, con la esclavitud quedan castigados sus pecados; si estos, Dios los humilla "para castigar sus pecados o para que se enmienden". Hechos, pues, esclavos, obedezcan a sus amos y no busquen su liberación sino conforme a derecho. Además, mejor es la condición de esclavo de un señor que la de esclavo de sus pasiones, como lo son tantos señores. Sean, pues, humildes, sumisos. Obedezcan escrupulosamente a sus amos, con gusto, con afecto, "como si fuera al Mesías"(Ef 6,5), según aconseja el Apóstol, convirtiendo así "su esclavitud en una especie de libertad", que de aquí a cien años todos calvos, amos y esclavos. "Pues pasará la injusticia, y será aniquilada toda soberanía y poder, y Dios lo será todo en todos"45.

Queda justificado el orden social de amos y esclavos, apuntalado además por Dios. Tranquilos todos. Los que no se quedaron tranquilos, y con razón, fueron los esclavos. Y porque forcejearon por salirse de su lugar y se desordenaron tenemos un orden social más justo.

Que las mujeres sigan obeciendo a sus maridos en todo, sin rechistar, de buena gana; incapaces de por vida para ser sujetos de derecho. Nada pueden hacer, ni siquiera en su adorno y vestido, sin permiso de sus maridos. $\mathrm{Ni}$ limosna pueden dar sin su consentimiento; tácito para pequeñas cantidades, expreso si se trata de sumas considerables ${ }^{46}$. La mujer es esclava de su marido. En las "tablas matrimoniales", actas del matrimonio, consta su compra por parte de él, que desde entonces es su señor ${ }^{47}$, "para la procreación de hijos"48. Y nunca olvide que "cualquier exceso en el modo requerido para la procreación es pecado"49; quizá venial, pero pecado, y ya se sabe que quien

44. De civ. Dei. XIX, 15.

45. Íb., íb.; cf. san Pablo, 1 Cor 7,$31 ; 15,24.28$.

46. Cf. Ep. 262, 4-11; fray Luis de León recogerá esta doctrina en La perfecta casada, Obras Completas Castellanas, edic. cit., IX, 283.

47. Cf. San Agustín, Serm. 37, 7.

48. Serm. 9, 18.

49. Íb., íb.; cf. Serm. 51, 22. 
desprecia los pecados veniales caerá en los mortales. Si a alguna le ha cabido en suerte, que no es suerte, sino Providencia de Dios, un marido borracho, adúltero y vapuleador, recuerde que es esclava y aguántelo dulcemente ( $j$ a saber si no será ella la culpable por deslenguada!). Quizá con su conducta lo gane para Dios, como lo ganó Mónica, su madre, dice Agustín ${ }^{50}$. Mas dejemos este discurso, no sea que convirtamos a Agustín en la bestia negra de las mujeres.

\title{
IV.- Consideración final
}

Volvamos a nuestros pensamientos. Paz, unidad, convivencia. Podemos citar textos y más textos de san Agustín y creer que con ellos nuestros problemas quedan resueltos. En realidad, no quedan ni formulados. No aportamos nada a la salida de la crisis, ni a la consolidación de los nuevos valores que apuntan en el horizonte y que, ojalá sea así, conformarán la sociedad futura. Conozcamos sí, a san Agustín; pero conozcamos también, y mucho mejor, el pensamiento actual, el sistema de ideas vivas de nuestro tiempo. Vivamos a la altura de las circunstancias, de nuestra circunstancia. Pensemos y hablemos desde ella. Ellacuría hablaba de un imperativo ético articulado en tres momentos: hacerse cargo de la realidad (estar enterado), encargarse de ella (hacerse responsable) y cargar con ella (apechugar con las consecuencias, "cargar con la cruz", que dice el evangelio (Mt 16, 24)). Pensemos nosotros, cada uno por sí mismo, no la sociedad, el entramado cultural, pasado o presente, en nosotros, y hablemos nosotros por nuestra cuenta y razón, cada uno por sí mismo, responsablemente, no los otros, pasados o presentes, en nosotros. Abrir este mundo a Cristo, crucificado y resucitado, debe ser nuestra principal tarea personal y comunitaria. Condición previa es que nos abramos a él cada uno de nosotros y que nuestra convivencia sea transparente fanal por él esclarecido; que "empiece a brillar vuestra luz entre los hombres; que vean el bien que hacéis y glorifiquen a vuestro Padre del cielo"(Mt 5,16).

\author{
José VEGA, OSA \\ Estudio Teológico Agustiniano \\ Valladolid
}

50. Cf. Confess. IX, 9, 19.22. 